\title{
Commentary
}

\author{
ROLAND LITTLEWOOD
}

\section{COMMENTARY: GLOBALIZATION, CULTURE, BODY IMAGE, AND EATING DISORDERS}

As with any other social fact, one can interpret an illness as somehow characteristic of the particular society in which it is found. Such specificity has been a continuing problem for comparative studies in psychiatry. Can those patterns recognized by medicine as "culture-bound syndromes" be fully explained through an understanding of one particular society? Or should these patterns be subsumed under more universal categories? Or, more modestly, should they be placed in groups whose members merely demonstrate some family resemblances to each other? Can we argue both-local specification and superordinate category-when a "behavioral syndrome appearing in widely differing cultures takes on local meaning so completely that it appears uniquely suited to articulate important dimensions of each local culture, as though it had sprung naturally from that environment" (Good and Good 1992: 257)?

Whether some general category adequately subsumes a characteristic local experience is fundamental for any human science. The case of medicine is complicated by its claim to demonstrate biological reality- so that individual illnesses can be identified as instances of some natural category that exists "out there" independently of any local interests in which it appears embedded, our own included. The question recalls anthropology's debates, less as to whether tabu or mana are categories that transcend local particularities, than as to whether sexual avoidance of close kin by nonhuman primates is homologous to incest prohibition, or whether it is merely analogous, primate sexual "avoidance" then being an inappropriate extrapolation from our human concerns.

Most arguments about eating disorders now recognize something "cultural" as essential in their etiology; whether body imagery or women's social and family experience (Nasser et al. 2001). Support for women's "fear of fatness" as the discrete cause in Western societies comes from a diversity of theoretical approaches (Littlewood 1995). "Fear of fatness" has accompanied economic and public health changes associated with industrialization: improved nutrition and a general access to food beyond physiological requirements; the development of eating as a leisure activity, with a dislocation of palativeness from nutritiousness through the development of "cuisine" and the commodification of cooked foods; lower mortality rates but reduced fertility; and an increase of women in the labor market competing Culture, Medicine and Psychiatry 28: 597-602, 2004. 
against men. This has in turn led to a theoretical but in practice not so accessible moral equality and perhaps identity with men; a resulting different "fit" between social role, goals, class status, child bearing, and body morphology, with a deemphasis on women's subdominant maternal and domestic roles and a general discomfort with generational distinctions (Giddens 1991); and even a possibly related shift in male sexual attraction to an androgynous and "younger" female body, perhaps as a response to feminism (Bordo 1993; Littlewood 2002).

In contrast, relative plumpness in women in nonindustrial societies, while rarer, has been said to demonstrate health and prosperity (Brown and Konner 1987; Furnham and Alibhai 1983; Lee et al. 1992; Polhemus 1978). There is ample evidence of a cultural shift in European societies toward a preference for a thinner, "slimmer" female body form, but no agreement as to why this has occurred or whether it is fundamental to the etiology of eating disorders. Let us start from the biological and political context. A number of general characteristics can be identified: absolute and relative wealth, industrialization, urbanization, literacy, and formal education, commodification of cooked food with a disjunction between taste and nutrition, lower fertility and mortality rates, later age of marriage, the absence of prescriptive marriage patterns, the recent development of nationalism (an equation of the state with language, shared history and ethnic identity), and an immediate relationship with global capitalism and its contractual and entrepreneurial values. One overarching characteristic which has attracted some attention, given the emphasis on the role of autonomy and self-expression in eating disorders, has been what may be termed "modernization" (Deutsch 1991).

"Modernization" theorists argue that there has been a historical shift, driven by technological development, in social structure and patterns of marriage: away from personal status determined by kinship or other ascribed corporate membership to more contractual and individualized roles. This in turn leads to an earlier and more complete independence of children from their parents; greater geographical and social mobility; less ascription of identity through caste, kinship, or gender; together with literacy, tolerance, secularization, and cultural pluralism, with greater value placed on self-determination, achievement motivation, and future orientation. Modernization also brings decontextualization and differentiation out of a once enmeshed social domain of nutrition, comportment, sexuality, kinship, economics, politics and religion with the internalization of social constraints into the embodied self (Bordo 1993; Hall and Jarvie 1992; Morris 1991; Turner 1992).

Eating disorders now no longer appear so highly specific to women of European origin (Bryant-Waugh and Lask 1991; Dolan et al. 1990; Lee 1997; Mumford and Whitehouse 1988; Nasser 1986). When an identified clinical pattern bears a close relationship to cultural expectations, as has been argued for eating disorders, there are, as we have seen, problems of definition and comparison. Increasing convergence of psychopathology may be a convergence of the local meanings of the 
measures. Selection of cases will be biased through any local institutionalization of food restriction, such as licensed ascetism or extended fasting (but see Bhadrinath 1990; Littlewood 1990; Ritenbaugh et al. 1993). But there are no studies of the perception of "normal" and "abnormal" self-starvation by, say, South Asian communities. In the same way, it can be difficult to distinguish an eating disorder in the West from the normative expectations of body mass among dancers, or from such "ritualized" patterns as periodic purging before examinations in American college sororities. The preferred methodology will be one which examines the contours of the pattern, not just in putative cases, but in a wider sample from the particular culture.

Recent studies do suggest no invariant cross-cultural association between ideals of personal morphology and symptomatology. For example, young adults in North India, thinner than Asian or white Britons, would ideally like to weigh more than they do, especially the men but also the women (Schmidt and Bakshi 1993). Thus, attempting to lose weight, the major determinant of the development of eating disorders argued by clinicians for Western populations, is absent, and yet these young adults' scores of the BITE (which assesses bulimia) are not significantly lower. Indeed both men and women in Jaipur have higher BITE scores than do European men in London. Thus, bulimic perceptions and actions seem not uncommon in this Indian group, but again they appear distinct from a specific concern with body fatness. By contrast, in Lahore, a city with a now established "dieting culture" and with similar average body mass indices to British Asians, a concern with body fatness does correlate with Eating Attitudes Test (EAT) measures (Mumford et al. 1992). Mumford and Whitehouse (1988), Mumford et al. (1991), and Dolan et al. (1990) find higher EAT scores among Asian girls in Britain than among Europeans, but again no greater concern with fatness. Whilst Asian British students do seem similar to white students in terms of weight and shape dissatisfaction (Schmidt and Bakshi 1993), they have a higher prevalence of clinical bulimia. Taking these studies together with Lee's (1997) data suggests that "bulimia" among South Asians may be seen as something other than just a statistical reflection of general pressures against fatness.

Whether these findings in themselves argue for personal recourse to eating disorders as a specific and instrumental mode of self-determination is uncertain. Self-starvation might simply be the most accessible way of generally expressing distress and soliciting others, particularly parents and family members, in any context where food refusal denotes illness, and where past nurturance and current solidarity are articulated through an idiom of shared food prepared and distributed by women. Whether in all societies eating restriction is particularly salient in articulating conflicts about female autonomy, in subjective identity or as an instrumental communication in the family milieu, is uncertain. However, given the Jaipur study and similar studies of schoolgirls elsewhere in northern India, 
which found high scores on the EAT (King and Bhugra 1989), one might consider whether something like the cultural preconditions for "ascetic self-starvation" already hold for South Asian societies and thus provide an available model for severe food restriction quite independent of any fear of fatness.

We cannot presume that the final common pathway of self-starvation is reached in Africa, India, the Far East, Britain, or elsewhere by the identical antecedents, but at a high level of generality we might argue for analogous subjective and objective renunciations by women, a limited self-determination through extreme self-denial. And it is precisely in the ambiguous shift to "modernity," with the loss of other instrumental strategies of personal resistance and the ubiquity of potentially unlimited consumption, that these become heightened through the medicalized emphasis on a purified and self-sufficient body as the locus of personal agency.

So, are eating disorders in the non-Western world associated with:

i. Acculturation to a "fear of fatness" and the pervasive influence of Western body imagery?

ii. Internalization of Western concepts of individual autonomy and competitive individualism, and perhaps with associated ideas of romantic love and companionate partnerships?

iii. Some modifications of existing local patterns of dieting and self-denial in females?

iv. And do they occur as a stage of transition to Westernized societies?

The five articles presented here together deal with these possibilities. The article on Japanese findings, by Pike and Borovoy, emphasizes that whilst "thinness" is valued, marriage and motherhood still guarantee personal security (but with little personal autonomy). Eating disorders are then less a simple striving for autonomy than a questioning and negotiating of constraints. Becker's article on Fiji shows how identification with an idealized image of the characters of Western television drama occurs both in terms of gender power and slimness, but is also associated with the pragmatics of getting valued jobs.

By contrast, in San Andrés, Belize, the article by Anderson-Fye argues traditional body shape is locally seen as immutable and God-given, and celebrated in frequent beauty pageants; indeed any pressure to diet seems to come from individual parents concerned about the employment prospects of their offspring in the face of tourism. For me this recalls the situation in West Indian islands further east, but in the contribution from Curaçao, Katzman and her colleagues report earlier levels of anorexia nervosa similar to Western Europeans. In their current article they return to look in greater detail at the cases using a more qualitative approach. They find that anorexia nervosa in Curaçao is associated with a significant period of life outside the island (with the return of migrants and students), and it seems to 
express threats to identity in terms of ethnicity and family and female roles. From South Africa comes a paper (by Grange, Louw, Breen, and Katzman) which highlights a perennial concern of cultural psychiatry (Littlewood 2002): high scores on a standardized European questionnaire suggest higher rates of bulimia and anorexia nervosa pathology among black African schoolchildren compared with local white and "mixed-race" children, but it appears there are big problems not only with translating the standardized format so that responses in the new context may have quite different meanings, but with the whole political environment of cross-cultural research in contemporary South Africa. Together the papers usefully illustrate the current common ground in the comparative study of eating disorders: their methodology, scope and dilemmas.

\section{REFERENCES}

Bhadrinath, B.R.

1990 Anorexia Nervosa in Adolescents of Asian Extraction. British Journal of Psychiatry 156: 565-568.

Bordo, S.

1993 Unbearable Weight: Feminism, Western Culture and the Body. Berkeley: California University Press.

Brown, P.J., and M. Konner

1987 An Anthropological Perspective on Obesity. Annals of the New York Academy of Sciences 499: 29-46.

Bryant-Waugh, R., and B. Lask

1991 Anorexia Nervosa in a Group of Asian Children Living in Britain. British Journal of Psychiatry 158: 229-233.

Deutsch, E., ed.

1991 Culture and Modernity. Cambridge, MA: Harvard University Press.

Dolan, B., J.H. Lacey, and C. Evans

1990 Eating Behavior and Attitudes to Weight and Shape in British Women from Three Ethnic Groups. British Journal of Psychiatry 157: 523-528.

Furnham, A., and N. Alibhai

1983 Cross-Cultural Differences in the Perception of Female Body Shapes. Psychological Medicine 13: 829-837

Giddens, A.

1991 Modernity and Self-Identity: Self and Society in the Late Modern Age. Oxford: Polity.

Good, B., and M.J.D. Good

1992 The Comparative Study of Greco-Islamic Medicine: The Integration of Medical Knowledge into Real Symbolic Contexts. In Paths to Asian Medical Knowledge. C. Leslie and A. Young, eds. Berkeley: University of California Press.

Hall, J.A., and I.C. Jarvie, eds.

1992 Transition to Modernity: Essays on Power, Wealth and Belief. Cambridge: Cambridge University Press.

King, M.B., and D. Bhugra

1989 Eating Disorders: Lessons from a Cross-Cultural Study. Psychological Medicine 19: 955-958. 
Lee, $S$.

1997 Reconsidering the Status of Anorexia Nervosa as a Western Culture-Bound Syndrome. Social Science and Medicine 42: 21-34.

Lee, S., L.K.G. Hsu, and Y.K. Wing

1992 Bulimia Nervosa in Hong Kong Chinese Patients. British Journal of Psychiatry 161: $545-551$.

Littlewood, R.

1990 From Categories to Contexts: A Decade of the "New Cross-Cultural Psychiatry." British Journal of Psychiatry 156: 308-327.

1995 Psychopathology and Personal Agency: Modernity, Culture Change and Eating Disorders in South Asian Societies. British Journal of Medical Psychology 68: 45-63.

2002 Pathologies of the West. London: Continuum/Cornell University Press.

Morris, B.

1991 Western Conceptions of the Individual. Oxford: Berg.

Mumford, D.B., and A.M. Whitehouse

1988 Increased Prevalence of Bulimia Nervosa Among Asian Schoolgirls. British Medical Journal 297: ii, 718.

Mumford, D.B., A.M. Whitehouse, and M. Platts

1991 Sociocultural Correlates of Eating Disorders Among Asian Schoolgirls in Bradford. British Journal of Psychiatry 158: 222-228.

Mumford, D.B., A.M. Whitehouse, and I.Y. Choudry

1992 Survey of Eating Disorders in English-Medium Schools in Lahore, Pakistan. International Journal of Eating Disorders 11: 173-184.

Nasser, $\mathrm{M}$.

1986 Comparative Study of the Prevalence of Abnormal Eating Attitudes Among Arab Female Students of Both London and Cairo Universities. Psychological Medicine 16: 621-625.

Nasser, M., M. Katzman, and R. Gordon, eds.

2001 Eating Disorders and Cultures in Transition. New York: Brunner-Routledge.

Polhemus, T.

1978 Preface. In Social Aspects of the Human Body. T. Polhemus, ed. Harmondsworth: Penguin.

Ritenbaugh, C., M. Weiss, D. Parron, C.L. Shisslak, N. Teufel, T.K. Leonard-Green, and R. Prince

1993 Eating Disorders. In Revised Cultural Proposals for DSM-IV; Submitted to the DSM-IV Task Force by the Steering Committee, NIMH-Sponsored Group on Culture and Diagnosis. J.E. Mezzich, A. Kleinman, H. Fabrega, D. Parron, B.J. Good, G. Johnson-Powell, K.M. Lin, and S. Manson, eds. Unpublished manuscript. Schmidt, U., and N. Bakshi

1993 Personal Communication.

Turner, B.

1992 Regulating Bodies: Essays in Medical Sociology. London: Routledge.

ROLAND LITTLEWOOD

Department of Anthropology

University College of London

Gower Street

London WCIE $6 B T$

$U K$

E-mail:r.littlewood@ucl.ac.uk 